\title{
General Health, Dental Status \& Perceived Dental Treatment Needs of An Elderly Population in India
}

\author{
Utkarsh Shishodia $^{1^{*}, \text { Sukreeti Krishan }}{ }^{2}$, Subham Sharma ${ }^{1}$, Vaibhav Anand ${ }^{1}$, Mohit \\ Kaushik $^{1}$ \\ ${ }^{1}$ Department of Prosthodontics Crown Bridge \& Implantology, Himachal Institute of Dental Sciences, Paonta \\ Sahib, Himachal Pradesh, India \\ ${ }^{2}$ Departmentof Periodontology, Himachal Institute of Dental Sciences, Paonta Sahib, Himachal Pradesh, India
}

*Correspondence

Dr.Utkarsh Shishodia

Department of Prosthodontics Crown Bridge \& Implantology, Himachal Institute of Dental Sciences, Paonta Sahib, Himachal Pradesh, India.

Email: $\underline{\text { utkay01@gmail.com }}$

\begin{abstract}
Objectives: This pilot study determined the general and dental health status; perceived medical and dental treatment needs of an elderly population dwelling in residential homes in Himachal Pradesh (India).Method: Subjects were chosen from OPD of Department of Prosthodontics \& Implantology, Himachal institute of dental sciences, Paonta sahib, (H.P) between April 2020 - April 2021. ( $\mathrm{N}=133$, female: 71 and male: 62) were involved in this study. A detailed questionnaire was prepared and dental examinations were conducted. Information was collected related to age, education levels, financial status, current physical functional status, general health, mental health, previous dental history, current dental status, oral hygiene practices and denture hygiene of these elderly people. The prevalence of edentulism, the presence and type of dental prostheses, dental and denture status and denture cleanliness were further evaluated.Results: The three most prevalent reported general health problems were associated with Genito-urinary problems (24\%) followed by cardiovascular (18\%) and respiratory problems (14\%) varying significantly between genders, with males suffering more from cardiovascular problems than females ( $\mathrm{p}<$ 0.05). Females showed significantly higher gastrointestinal and orthopaedic problems than males ( $\mathrm{p}<0.05$ ). Females were more frequently edentulous than males but denture hygiene was significantly better in females than in males $(\mathrm{p}<0.05)$. Brushing frequency did not significantly increase denture hygiene $(\mathrm{p}=0.6)$. More than one-third of the subjects had not been to the dentist within the previous 5-10 years, mainly due to lack of demand, followed by the cost of the dental care and fear. More than two-thirds of denture-wearing subjects wore their dentures only during eating.
\end{abstract}

Keywords: Dental Health, dental prostheses, dental care.

This is an Open Access article that uses a fund-ing model which does not charge readers or their institutions for access and distributed under the terms of the Creative Commons Attribution License (http://creativecommons.org/licenses/by/4.0) and the Budapest Open Access Initiative (http://www.budapestopenaccessinitiative.org/read), which permit unrestricted use, distribution, and reproduction in any medium, provided the original work is properly credited.

\section{Introduction}

In 1990, the populace was once estimated to be around 5 billion humans with $75 \%$ of them living in underdeveloped countries [1,2]. In India, the population of sixty-five years aged and older was predicted to be around 7.5 million $(12.5 \%)$ of the total population.

Nowadays, one of the most important issues in dentistry is managing dental care of the geriatric patients. To solve this problem, most of the developed nations, Investigated dental and general health status of the geriatric population in their respective countries.

Although the general and dental health care of the aged were being acknowledged in some of the developed countries, but there is no such system to identify the problem and provide adequate care in accordance to the needs of the patients. On the other hand, whilst oral problems are hardly ever life-threatening, but they can have a sizable effect on the social and physiological well-being of geriatric subjects.

It is also assumed that good oral health is proportional to the quality of life in geriatric subjects, this becomes evident due to the fact that many of these subjects have disabilities and sometimes handicap which results in impaired oral health. 
This state of affairs may lead to poor oral health and oral ailments in the geriatric population \& is a topic of concern for the society.

Geriatric dentistry has gained popularity but still there is lack of comprehensive data on oral health and needs of the geriatric population in India. There is a strong need for epidemiological research on the oral health of geriatric subjects and its evaluation with cross-sectional studies.

It may also be indispensable in the future to verify whether the conditions observed in the geriatric population are on the rise or are sections of a cohort phenomenon.

The main motive behind this pilot study were to investigate the dental health status and the oral care needs of geriatric subjects in Himachal Pradesh, India.

\section{Materials and Methods \\ Subjects}

A distinct questionnaire was fabricated to collect statistics associated with age, civil status, education levels, monetary status, mental health, physical status and how they experience their health, previous dental history (frequency of dental visit and reasons), current oral status, duration of denture wear if any, choice of diet, oral hygiene practices (use of floss, brush, or both), and denture hygiene and means of preserving hygiene (soap, paste, water, mouthwash) among the geriatric population (65 years and older), the subjects were chosen from the general OPD of Department of Prosthodontics \& Implantology, Himachal institute of dental sciences, Paonta sahib, (H.P) between April 2020 - April 2021.

The principal investigator carried out all oral examinations. No intra-oral radiographs were taken. The prevalence of edentulousness, the presence and type of dental prostheses, dental and denture status and denture cleanliness had been similarly evaluated.

Mental health of the subjects was evaluated on the basis of questionnaire described by Kondo et al.[3] Intra-oral examination was done using an intra-oral mirror and probe with patients sitting under natural light. During the oral examination, remaining natural teeth, the kind of prostheses (complete or partial denture), and the balance and retention of the prostheses were recorded.

The subjects were categorized according to their oral status, particularly edentulous ones except for dentures or with solely one complete denture, edentulous with two complete dentures and dentate with partial dentures[4]. Subjects were checked for dental health status natural teeth, restorations and status of hard and soft tissues as well. The DMF-T index, which represents the usual dental status, was calculated for every patient[5]. Parameters applicable to periodontal prerequisites have not been evaluated.

\section{Evaluation}

Evaluation of the state of the existing fixed and removable prostheses and replacement needs, was done using two Indices: the Karlsson's index[6] for the crowns and fixed-dental-prosthesis (FDPs), and the modified Nevalainen's index[7] for the partial and complete dentures. The index to examine the need for replacement of partial and entire dentures by Nevalainen et al.[7] was modified and used in the clinical assessment of the dentures for stability and retention. The dentures with poor retention or these with extensive cracks and fractures had been considered for repair.

Denture cleanliness is examined by a plaque-disclosing medium (proflavine mono-sulphate in $0.3 \%$ aqueous solution) to check for plaque accumulation on the surfaces of the maxillary dentures. Based on the extent of plaque on the denture base, a formerly described index was used for classification of denture cleanliness[8]

- $\quad$ Excellent: None or solely few spots of plaque;

- Fair: More prolonged plaque, much less than half of the denture base;

- $\quad$ Poor: More than half of denture base blanketed is by plaque.

\section{Statistical Analysis}

The statistical evaluation is carried out using the SAS System for Windows, launch 8.02/2001 (Cary, NC, The USA). The facts were been analysed by evaluation of variance (ANOVA) and chi-square tests. $p$ Values less than 0.05 have been regarded to be statistically significant in all tests results.

\section{Results \\ Age and Education}

The age of the pattern populace ranged between 65 years and 90 years, of whom $47 \%$ have been male and 53\% have been female. Overall, for each male and female, two-thirds of the study group was between 65 and 70 years of age, one-third was once between 70 and 80 years and solely a few were over eighty years of age (Fig. 1). $35 \%$ of the subjects have been widows, $22 \%$ unmarried and $31 \%$ married. From the educational standpoint, whilst one-fifth $(21 \%)$ of the study population had in no way been to college. 


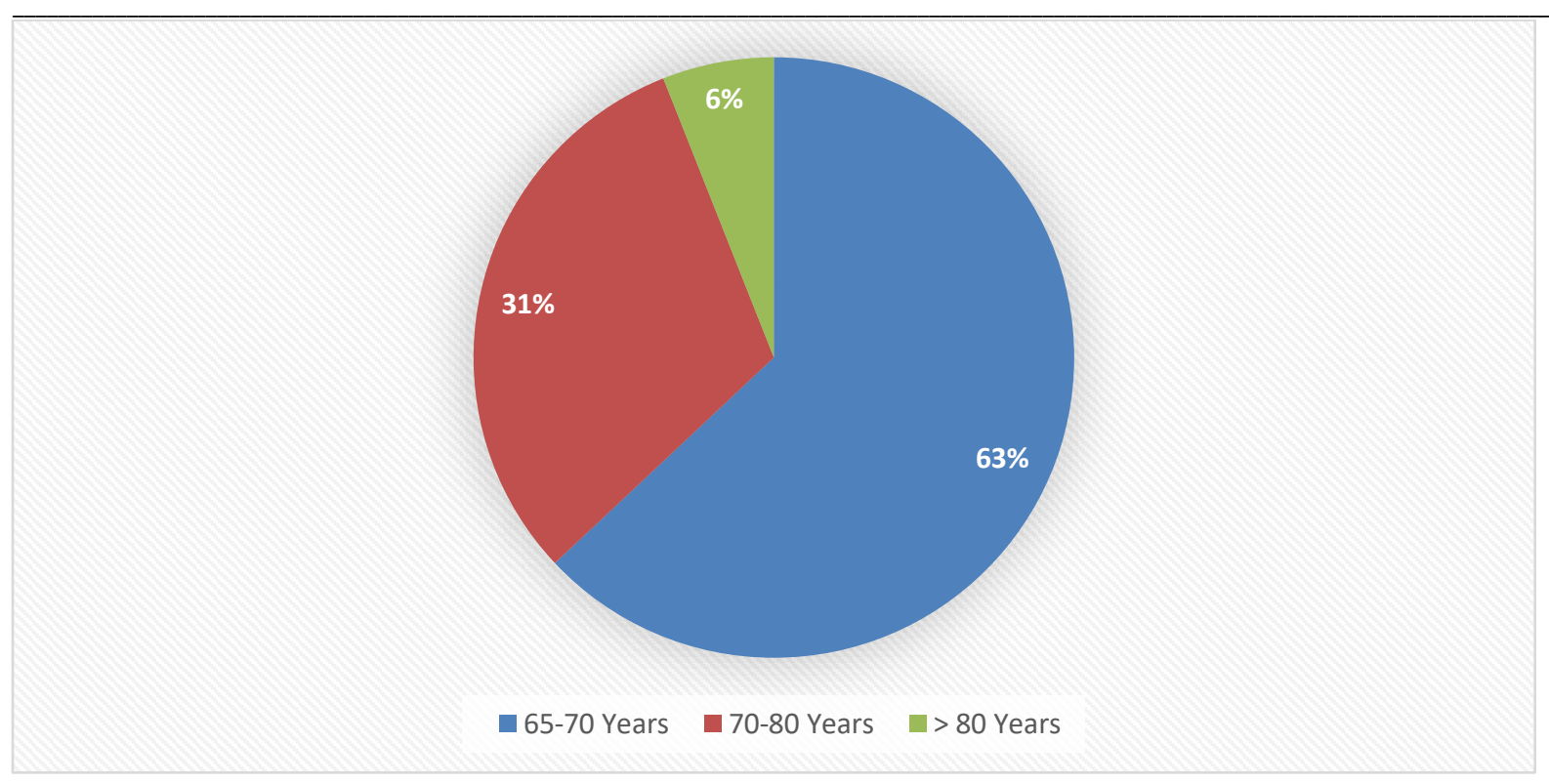

Fig. 1: Age Distribution

\section{Financial Status}

More than $1 / 2$ of the subjects $(57 \%)$ had an annual personal earnings less than 30000 INR and were receiving other help from their families. Only a minority had an annual income more than 1 lakh/anum (Fig. 2). Despite the low annual income, more than half of (55\%) of the subjects suggested that their earnings were simply enough to meet their wishes and needs (of those, $80 \%$ have been in the National Pension Scheme, and 20\% had their own source of income).

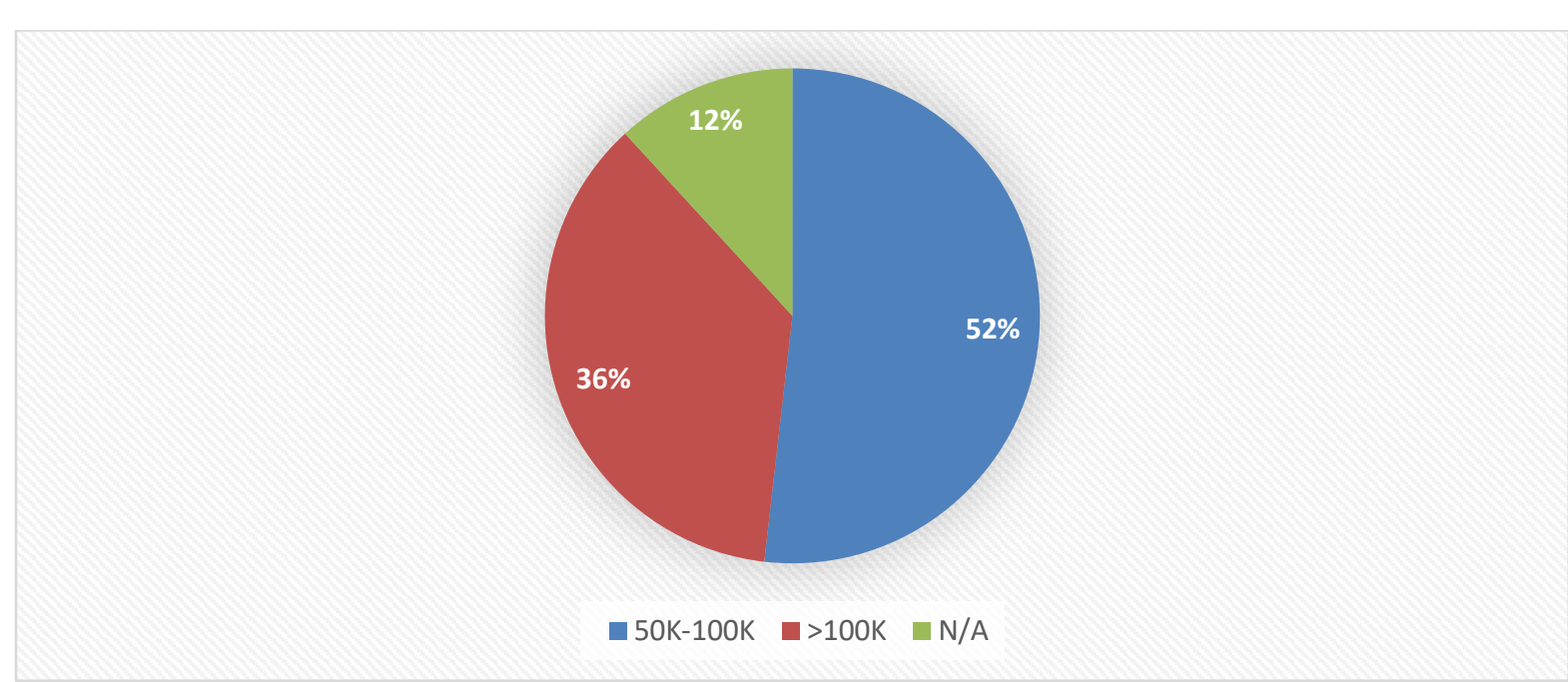

Fig. 2: Financial Status

Table 1 : Education and financial status

\begin{tabular}{|l|l|l|l|}
\hline & No education & Primary school & Higher education \\
\hline Edentulousness & $59 \%$ & $33 \%$ & $8 \%$ \\
\hline & LOW INCOME & AVERAGE INCOME & HIGH INCOME \\
\hline Edentulousness & $50 \%$ & $42 \%$ & $8 \%$ \\
\hline
\end{tabular}


Among denture wearers $72 \%$ suggested that their dentures have been worn solely for eating. For preference of weight loss program, $12 \%$ of the subjects reported consuming tough food, $58 \%$ a combination of hard and soft food, and 30\% reported eating only soft food.

\section{Oral Hygiene Practices}

An assessment of oral hygiene practices of the dentate population gave the following results, $81 \%$ of the group had never flossed their enamel and $31 \%$ brushed their tooth very less often.

\section{Denture Hygiene}

Twenty-six percent of the denture wearing subjects cleaned their dentures. Most of them cleaned their dentures by way of brushing with cleaning soap or toothpaste and water. Only a few cleaned their dentures by soaking them in a solution. In a smaller group, blended brushing and soaking techniques had been being practiced (Fig. 3). The great majority of the topics by no means used a mouthwash, and solely 3\% used mouthwashes either each day or weekly. The others both immersed their dentures in water or did no longer practiced any cleaning regimens.

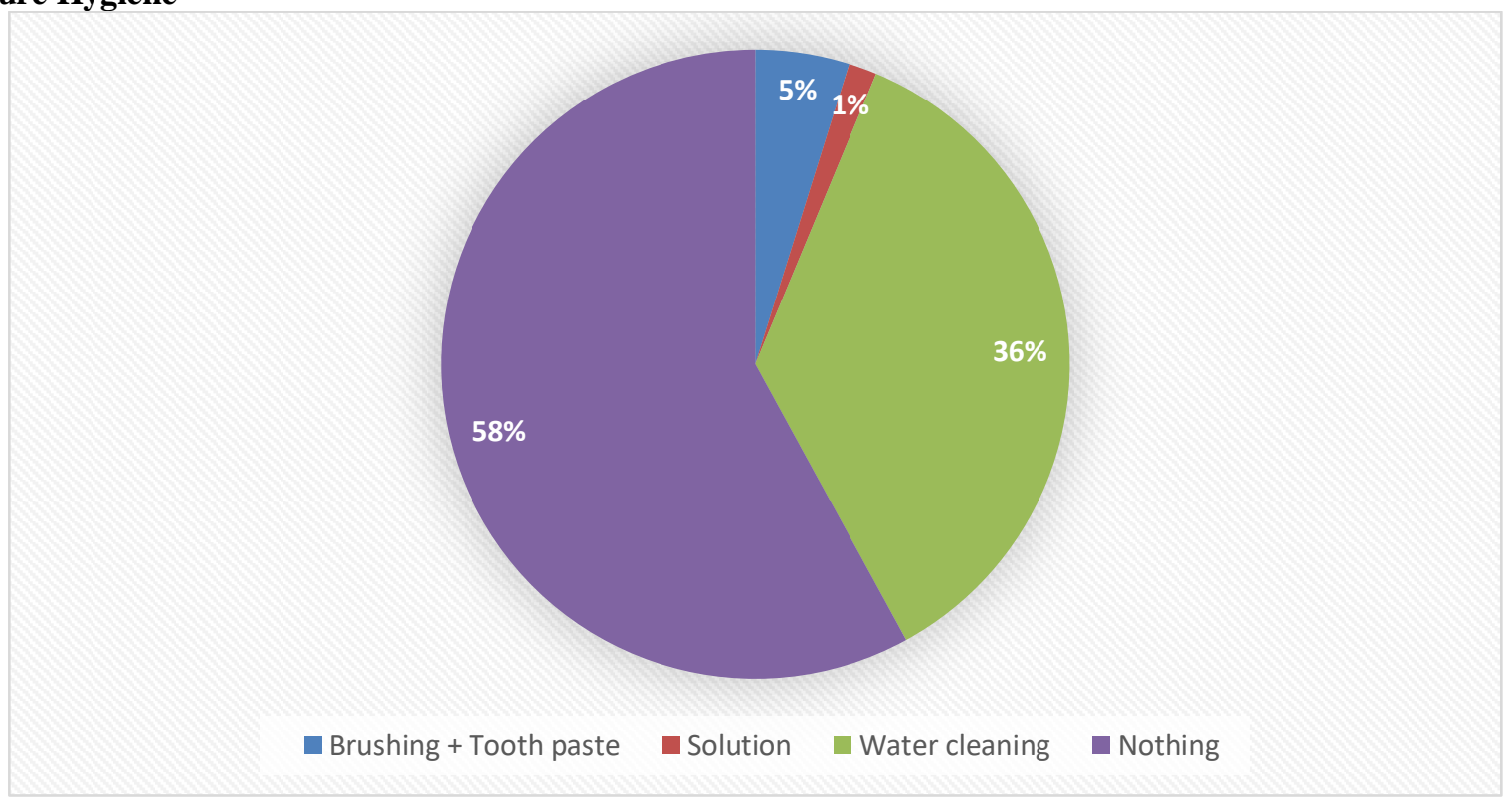

Fig. 3: Denture Hygiene

In the fifty-seven women sporting dentures, $23 \%$ had denture hygiene (Table 2). There were big variations excellent, $54 \%$ good and $23 \%$ had poor denture hygiene. In the 35 denture-wearing males, only $3 \%$ had excellent between genders and their degree of denture hygiene $(\mathrm{p}$ $<0.0001)$. In assessing

Table 2 : Oral Hygiene

\begin{tabular}{|l|l|l|l|}
\hline & Excellent & Fair & Poor \\
\hline Male & $3(9)$ & $5(14)$ & $27(77)$ \\
\hline Female & $13(23)$ & $31(54)$ & $13(23)$ \\
\hline
\end{tabular}

the relationship between denture hygiene and brushing frequency, $38 \%$ of the subjects who had an excellent denture hygiene brushed their tooth much less. Interestingly, more than two-thirds of the subjects who had poor denture hygiene said that they brushed their teeth more in a day (Table 3).

Table 3 : Relationship between Brushing and Oral Hygiene

\begin{tabular}{|l|l|l|l|}
\hline & Excellent & Fair & Poor \\
\hline Less Than Once & 38 & 19 & 8 \\
\hline Once A Day & 12 & 56 & 15 \\
\hline More Than Once & 50 & 24 & 78 \\
\hline
\end{tabular}


Brushing frequency did not appreciably increased the denture hygiene $(p=0.6)$. When the relationship between education and denture hygiene stages used to be compared, $20 \%$ of the pattern whose dentures had poor cleanliness had in no way been to school, $40 \%$ had been to some college and $40 \%$ had experienced higher education.

\section{Discussion}

Studies assessing each the scientific and oral health of older adults are no longer common. In this study, the most common clinical problems said have been cardiovascular and Genito-urinary issues for males and orthopaedic, genitourinary, gastrointestinal and respiratory troubles for females. Although the percentages had been no longer as excessive as these in this study, in preceding reviews, comparable tendencies have been seen primarily for cardiovascular ailments observed by orthopaedic and gastrointestinal problems [9].

With appreciation to the contemporary dental findings, we learn about the populace introduced with $60 \%$ edentulism in these over sixty-five years of age. This study is similar to a British study where the charges of edentulism ranged between $54 \%$ and $61 \%$, Other records from Australia, Denmark, Scotland, Norway, and Ireland in the past indicated greater edentulism, ranging from $75 \%$ to $80 \%$.

Nevertheless, in Western Europe, the rate of edentulism has changed significantly during the last decade ranging between $35 \%$ and $40 \%$ of the population [10-14]. When compared with these figures, our findings are considerably lower. However, the pattern of edentulism is changing radically with projected reductions in edentulism throughout the industrialized world over the next 20-30 years [15-17]. It is expected that there will be edentulous patients in the future. For example, in Canada, [18] and the UK [19] this will last for another $30-40$ years, but the number of people without teeth is expected to fall over the next three decades to only $4 \%$ of the UK population [15].

Generally, the proportion of edentulism in older populations has regularly been used as an indicator of dental status [20-22].

On the other hand, dental visits had been now not very frequent, and approximately no greater than a quarter of the surveyed subjects had been to a dentist during the preceding year. Interestingly, greater than half of the studied populace did no longer sense the want or urge to go to a dentist, though their dental conditions were not ideal. This suggests in reality that dental treatments have been not inside their priorities. Notwithstanding, fees performed major roles in neglecting visits to the dentist. The reasons why dental care is no longer sought more regularly are generally complicated and contain many factors. Among these are variations between perceived and actual need, lack of mobility, and accessibility to care, fear of dentist, and excessive cost [23-25].

The median earnings of the Indian populace are approximately 1,30,00 INR - 1,50,00 INR in accordance with the modern-day report

by UNICEF. With regard to the earnings of the residents surveyed, it can be noted that nearly $1 / 2$ of the subjects fell below the common earnings level.

In a Canadian survey, the fee of dental visits within the previous 1-2 years was once between $52 \%$ and $70 \%$ when the survey was done almost 10 years ago (18). Other research has proven that as a population ages, visits to the doctors increases, while those to dentists decreases [26].

This pattern of care utilisation has been attributed to the increased chance of persistent systemic ailments and increased price of edentulousness related with ageing [23]. In 1977, a US countrywide Health Interview Survey stated that $63 \%$ of the customary population had made one or extra visits to the dentist that year whereas from non-institutionalised persons older than sixty-five years of age, solely $34 \%$ had made such a dental visit [1]. There should be two motives for this in that both the tooth play much less significance or the denture treatment does now not require visits to the dentist.

Based on these results, it cannot be noted that dentures are no longer needed because $72 \%$ of the denturewearing subjects reported that they would put on their dentures only for eating. On the different hand, needless to say wearing no dentures did not impair their different social things to do or their satisfactory of life. Marcus et al.[19] mentioned that $19 \%$ of the studied population had no dentures. Kuc et al. [18] made similar observations in a Canadian cohort and Samaranayake et al. [25] in a Scottish cohort where this determine used to be $17 \%$ and $20 \%$ respectively.

In the existing study, the fineness of the dentures was not ideal, specifically they required repairs or renewal from $90 \%$ of the in partially dentate subjects due to enamel loss and/or presence of residual roots. In some research it has been proven that edentulous subjects have inadequate dentures ranging between $31 \%$ and $80 \%$ $[13,18]$. In the present study, $85 \%$ of the evaluated complete dentures had been discovered to be inadequate. These values are comparable to that observed in two Canadian research that observed $67-81 \%$ of older adults had been in need of dental treatment [27,28].

The study additionally attributed to lack of obligatory visits to the dentist in India as it was noted that greater than one-third of the subjects had not been to the dentist for 5-10 years. The survey confirmed statistically 
significant differences in the edentulousness ratio between males and females, with the ratio being greater for the latter. This discovery is comparable to that of earlier surveys [29-32] that place greater occurrence of edentulism among females of all age groups.

This study displays the truth that research and conclusions derived from these are, via design, only valid for humans residing in such conditions. General statements consequently can't be made for the whole populace.

Furthermore, oral health programmes ought to be carried out with an emphasis on events preventative and preservation in addition to healing care. The nursing and the clinical personnel in specific must be informed, as they should design academic materials and different assets unique to the oral health needs of older adults, as cautioned previously.

To furnish dental care services, improve the current ones to meet these requirements and check out the needs per se may want to solely be realised with such surveys. Only then may want to progressive delivery programmes be hooked up to minimise the considerable dental fees required. One way of improving care for the aged is to make certain that health care employees apprehend the significance of regular dental care, oral and denture hygiene. Therefore, governments and foundations should immediately evaluate their dental health care systems.

\section{References}

1. Ettinger RL. Demography and dental needs: an international perspective. Gerodontology 1993; 10: 3-9.

2. Pack ARC. Dental services and needs in developing countries. Int J Dent 1998; 48: 239-247.

3. Kondo N, Kazama M, Suzuki K et al. Impact of mental health on daily living activities of Japanese elderly. Prev Med 2008; 46: 457-462.

4. Ramon T, Grinshpoon A, Zusman SP et al. Oral health and treatment needs of institutionalized chronic psychiatric patients in Israel. Eur Psychiatry 2003; 18: 101-105.

5. Lamy M, Mojon P, Kalykakis GL et al. Oral status and nutrition in the elderly.JOL. 1976; 22-25.

6. Karlsson G, Teiwik A, Lundstro"mAet al. Costs of periodontal and prosthodontic treatment and evaluation of oral health in patients after treatment of advanced periodontal disease. Community Dent Oral Epidemiol 1995; 23: 159-164.

7. Nevalainen MJ, Rantanen T, Narhi T et al. Complete dentures in the prosthetic rehabilitation of elderly persons: five different criteria to evaluate the need for replacement. J Oral Rehabil 1997; 24: 251-256.

8. Budtz-Jorgensen E, Bertram U. Denture stomatitis II. The effect of antifungal and prosthetic treatment. Acta Odontol Scand 1970; 28: 283-306.

9. Mcdermot RE, Hoover JN, Gaucher C. Self reported medical conditions and drug use among elderly dental patients. J Can Dent Assoc 1990; 56:219221.

10. Suominen-Taipale AL, Alanen P, Helenius $\mathrm{H}$ et al. Edentulism among Finnish adults of working age, 1978-1997. Community Dent Oral Epidemiol 1999; 27: 353-365.

11. Osterberg T, Carlsson GE, Sundh V. Trends and prognoses of dental status in the Swedish population: analysis based on interviews in 1975 to 1997 by Statistics Sweden. Acta Odontol Scand 2000; 58: 177-182.

12. Walls AW, Steele JG. Geriatric oral health issues in the United Kingdom. Int Dent J 2001; 51: 183-187.

13. Mu“ ller F, Nitschke I. Oral health, dental state and nutrition in older adults. Z Gerontol Geriatr 2005; 38:334-341.

14. Osterberg T, Carlsson GE. Dental state, prosthodontics treatment and chewing ability - a study of five cohorts of 70-year-old subjects. J Oral Rehabil 2007; 34: 553-559.

15. Steele JG, Treasure E, Pitts NB et al. Total tooth loss in the United Kingdom in 1998 and implications for the future. Br Dent J 2000; 189: 598-603.

16. Sheiham JG, Steele W, Marcenes G et al. Prevalence of impacts of dental and oral disorders and their effects on eating among older people; a national survey in Great Britain. Community Dent Oral Epidemiol 2001; 29: 195-203.

17. Minakuchi S, Takaoka S, Ito $\mathrm{J}$ et al. Factors affecting denture use in some institutionalized elderly people. Spec Care Dent 2005; 26: 101-105.

18. Kuc IM, Samaranayake LP, van Heyst EN. Oral health and microflora in an institutionalized elderly population in Canada. Int J Dent 1999; 49: 33-40.

19. Marcus PA, Joshi A, Jones JA et al. Complete edentulism and denture use for elders in New England. J Prosthet Dent 1996; 76: 260-266.

20. Allen PF, McMillan AS. A longitudinal study of quality of life outcomes in older adults requesting implant prostheses and complete removable dentures. Clin Oral Implants Res 2003; 14: 173-179.

21. Jonathan A, Ship O. Oral health in the elderly what's missing? Oral Surg Oral Med Oral Pathol Oral Radiol Endod 2004; 98: 625-626. 
22. Anastassiadou V, Heath MR. The effect of denture quality attributes on satisfaction and eating difficulties.Gerodontology 2006; 23: 23-32.

23. Ettinger RL. Attitudes and values concerning oral health and utilization of services among the elderly. Int J Dent 1992; 42: 373-384.

24. Pietrokovski J, Azuoles J, Tau S et al. Oral findings in elderly nursing home residents in selected countries: oral hygiene conditions and plaque accumulation on denture surfaces. J Prosthet Dent 1995; 73: 136-141.

25. Samaranayake LP, Wilkies CM, Lamey PJ et al. Oral disease in elderly in long term hospital care. Oral Dis 1995; 1: 47-51.

26. Ainamo A, Osterberg T. Changing demographic and oral disease patterns and treatment needs in the Scandinavian populations of old people. Int J Dent 1992; 42: 311-322.

\section{Source of Support: Nil}

Conflict of Interest: Nil
27. Locker D, Leake JL, Hamilton $\mathrm{M}$ et al. The oral health status of older adults in four Ontario communities. J Can Dent Assoc 1990; 56: 215-217.

28. Slade GD, Locker D, Leake JL et al. The oral health status and treatment need of adults aged 65+ living independently in Ottawa-Carleton. J Can Public Health 1990; 81: 114-119.

29. Bice TW, Rabin DL, Starfield BH et al. Economic class and use of physician services. Med Care 1973; 11:287-296.

30. Norheim PW. The use of dental services in a population in northern Norway. Acta Odontol Scand 1979;37: 285-292.

31. Hunt RJ, Beck JD, Lemke JH et al. Edentulism and oral health problems among elderly rural Iowans: the Iowa $65+$ rural health study. Am J Public Health 1985; 75: 1177-1181.

32. Weintraub AT. Dental needs and dental service use patterns of an elderly edentulous population. J Prosthet Dent 1985; 54: 526-531. 